\title{
Die Kunst in der Geschichte oder die Geschichte im Kunstwerk
}

Studien zur Genese und Funktion der >Wendung zur Geschichte in der materialistischen Literaturtheorie und in der literarisch-politischen Praxis antifaschistischer Schriftsteller in den 30er Jahren.

\author{
Inaugural-Dissertation \\ zur Erlangung der Doktorwürde des \\ Philosophischen Fachbereichs II \\ der \\ Julius-Maximilians-Universität zu Würzburg
}

vorgelegt von

Günther Heeg

aus Waiblingen

1976 
Tag der mündlichen Prüfung: 17. 1./8. 2. 1977

Referent: Prof. Dr. E. Rotermund

Korreferent: Prof. Dr. H. Rombach

ISBN 978-3-476-99614-5

ISBN 978-3-476-99613-8 (eBook)

DOI 10.1007/978-3-476-99613-8 
Für Sascha und Klaus 


\section{INHALTSVERZEICHNIS}

Einleitung ..................... . . 1

A. Das große Bündnis: Die Volksfront und der bürgerliche Humanismus 7

I. Das Bündnis zwischen bürgerlichem und proletarischem Humanismus

1. Geist und Widergeist. Die Faschismusauffassung der bürgerlich-demokratischen Schriftsteller 10 - a) Die Rolle der demokratischen Schriftsteller in der Weimarer Republik 10 - b) Das Selbstverständnis der bürgerlichen Schriftsteller im Exil 12 - 2. Sozialismus als Geschichtszeichen. Bürgerliche Humanisten und die Sowjetunion $17-$ a) Die bürgerlichen Intellektuellen als neue Bündnispartner der proletarisch-revolutionären Schriftsteller 17 - b) Der 1. Allunionskongreß der Sowjetschriftsteller (1934) 19 - 3. Geschichtsphilosophie der Volksfront. A. Kurellas Theorie des sozialistischen Humanismus 25

II. Die historische Rechtfsertigung der Volksfront. Das 'Kulturerber als Grundlage des antifaschistischen Bündnisses . . . . . . . .

1. Der Kampf um die Rettung der Nation. Zur politisch-ökonomischen Begründung der Bündnispolitik 30 - a) Die Hinwendung zur "ganzen Nation«: Antifaschismus als Antiabsolutismus $30-$ b) Die Einheit der Nation als Zwangsdurchsetzung der Akkumulation des Kapitals $32-2$. Die Suche nach der revolutionären Tradition im skulturellen Erber $34-$ a) Von der Abwehr der faschistischen Geschichtsfälschung zur These von der Aktualität der bürgerlich-demokratischen Volksrevolution 34 - b) Die Kompensation der abgebrochenen Tradition der bürgerlich-demokratischen Revolution durch die nationale Kultur 38

III. Traumbilder. Bechers poetische Verbindung von Vergangenheit und Zukunft . . . . . . . . . . . . . . . . . .

1. Das ,Erber als ,Traumbesitz 41 - 2. Das 'poetische Prinzip oder das Neue im alten Gewand 46

IV. Georg Lukács’ Programm einer ästhetischen Erziehung . . . . . .

1. Vorgeschichte als Geistergeschichte: Die Volksfront und die revolutionäre Demokratie von 1789 bis 184848 - a) Asthetischer und politischer Fortschritt oder der Einfluß der Volksfront auf die Literatur 48 - b) Von der liberalen zur revolutionären Demokratic. Die Dialektik der Legitimation 50 2. Geschichtsphilosophie der Gattungen (I): Der dramatische Verlauf der 
bürgerlichen Revolution 52 - a) Das ästhetische Ideal des harmonischen Menschen $52-$ b) Die Kausalität des Schicksals (1): Zum geschichtsphilosophischen Ort der Tragödie bei Hegel. - c) Die Kausalität des Schicksals (2): Die Tragödie der revolutionären Demokratie 55 - d) Die Revolution als Schicksalswende im Leben der Intellektuellen 57 - 3. Geschichtsphilosophie der Gattungen (II): Die epische Welt der Volksfront 58 - a) Die Wanderungen des problematischen Individuums. Zur >Theorie des Romanse 58 - b) Die List der Vernunft in der Volksrevolution. Die Theorie des historischen Romans $60-4$. Flucht aus der Gegenwart oder Identifikation mit dem Aggressor? Zur Entwicklung des historischen Romans nach 184865

V. Der historische Roman der antifaschistischen Schriftsteller . . . . .

1. Feuchtwangers "Flavius Josephus« oder das historische Kostüm des Liberalismus $70-$ a) Zwischen Kulturkritik und Massenkultur: Der Schriftsteller als Repräsentant einer Geschichtsschreibung im Dienste des Lebens 70 b) Vernunft und Fanatismus. Die Abwehr der Massen $74-$ c) Die soziale Funktion des ästhetischen Historismus 77 - 2. Heinrich Manns "Henri Quatre oder die begonnene Selbstaufhebung des historischen Romans 81 a) Uberlegungen zur Aktualität des Königs Henri IV. 81 - b) Der Haß. Faschismus als mißglückte Nachahmung 85 - c) Die Güte. Kommunismus als neue Sittlichkeit 89

B. Die unaufgearbeitete Vergangenheit der bürgerlichen Gesellschaft: Das 'Kulturerbe in der faschistischen Massenbewegung . . . . . . .

I. Bürgerlicher Humanismus und völkischer Idealismus . . . . . . .

1. Egoismus und Freiheitsbewegung. [ber die Fesselung der Massen in der bürgerlichen Revolution 93 - 2. Zwischen Bourgeoisie und Proletariat: Die schiefe Rebellion des Mittelstands 97 - 3. Idealismus und Rigidität. Der Funktionswandel der kleinbürgerlichen Tugenden 99 - 4. Die Geschichte einer Verkehrung. Das Freiheitspathos des jungen Schiller und seine Erben 102

II. Der Gewaltcharakter der bürgerlichen Kultur. Brechts Aufsätze über den Faschismus . . . . . . . . . . . . . . . . . .

1. Der Bürger als Gangster: Die Verteidigung des Eigentums durch den Abbau der Kultur 110 - 2. Die Kontinuität bürgerlicher Erziehung im Nationalsozialismus 113 - 3. Heroischer Pauperismus - eine realitätsgerechte Ideologie 116

III. Brechts Modell einer historisch-praktischen Ideologiekritik am Ende der Weimarer Republik . . . . . . . . . . . . . .

1. Fortschreitende Praxis - rückständiges Bewußtsein. Der Ideologiebegriff im sDreigroschenprozeß 119 - 2. Ideologiekritik als Intellektuellenkritik: Exkurs zum >Tuismus، 123

IV. Die unaufgearbeitete Vergangenheit der bürgerlichen Gesellschaft: Gleichzeitigkeit und Ungleichzeitigkeit der faschistischen Massenbegung 
V. Original und Nachahmung: Reaktionen auf die Theatralik des Faschismus . . . . . . . . . . . . . . . . . .

1. Der Staatsmann als Schmierenkomödiant. Feuchtwangers satirischer Roman "Der falsche Nero « 130 - 2. Die Masken des Monopolkapitals. Zur marxistischen Periodisierung der bürgerlichen Gesellschaft 134 - 3. Der Nazi und das Unsägliche (Ernst Bloch) 137 - 4. Das Straßentheater der Nazis und das klassische Drama. Die Geschichte des skleinen großen Mannes im >Aufhaltsamen Aufstieg des Arturo Ui< 138

VI. Utopie und Taktik: Exkurs zu Blochs Theorie der unabgegoltenen Vergangenheit

1. Die Originalgeschichte des Dritten Reiches 149 - 2. Gustav Reglers Bauernkriegsroman »Die Saat« 152

VII. Ideologiekritik durch Montagen. Die Historizität ästhetischer Verfremdungstechniken ... . . . . . . . . . . . 158

1. Die Historisierung der Gegenwart $158-2$. Leokadja Begbick und der Schweyk. Plebejischer Materialismus als V-effekt 161 - 3. Funktion und Genese des völkischen Idealismus in "Die Rundköpfe und die Spitzköpfe $166-4$. Die Kunst in der Geschichte oder die Geschichte im Kunstwerk: Der >Dreigroschenroman als satirisches Modell 174

Anmerkungen .................. . 187

Literaturverzeichnis ... . . . . . . . . . . . 211

Register ..................... . 220 